Arq. Bras. Med. Vet. Zootec., v.65, n.3, p.722-728, 2013

\title{
Taxa de prenhez e de perda de gestação em receptoras de embriões bovinos produzidos in vitro
}

\author{
[Pregnancy and pregnancy loss rates in recipients of bovine \\ embryos produced in vitro] \\ A.L. Scanavez ${ }^{1}$, C.C. Campos $^{2 *}$, R.M. Santos ${ }^{3}$ \\ ${ }^{1}$ Faculdade de Medicina Veterinária - Universidade Federal \\ de Uberlândia - Bolsista de Iniciação Científica - Uberlândia, MG \\ ${ }^{2}$ Aluna de pós-graduação - Faculdade de Medicina Veterinária - Universidade Federal de Uberlândia, MG \\ ${ }^{3}$ Faculdade de Medicina Veterinária - UFU - Uberlândia, MG
}

\begin{abstract}
RESUMO
Avaliaram-se resultados de 1100 transferências de embriões, realizadas de novembro de 2008 a fevereiro de 2009, em um programa comercial de produção de embriões. Foram utilizados embriões $1 / 2$ Holandês/Gir (n=139) e 3/4 Holandês/Gir (n=961) de qualidade um e oitavo dia (D8) para transferência a fresco. As receptoras foram novilhas $1 / 2$ Nelore/Simental, sincronizadas, usando-se o protocolo: dia zero (D0) - introdução do dispositivo intravaginal com $1 \mathrm{~g}$ de progesterona $+2 \mathrm{mg}$ de benzoato de estradiol (BE); dia 5 (D5) - aplicação de $150 \mu$ g de D-cloprostenol $\left(\mathrm{PGF}_{2 \alpha}\right)+400 \mathrm{UI}$ de gonadotrofina coriônica equina (eCG); dia 8 (D8) - remoção do dispositivo intravaginal; e dia 9 (D9) - aplicação de 1mg de BE. Foram analisados os efeitos do grupo genético, o estágio de desenvolvimento e o tempo de cultivo do embrião, o lado do corpo lúteo (CL), o touro, o número de inovulações prévias realizadas em cada receptora e a sequência de horas de serviço gastas para realizar as inovulações sobre as taxas de prenhez e de perda da gestação. Apenas o tempo de cultivo do embrião influenciou a taxa de prenhez. Conclui-se que, ao utilizar embriões de excelente qualidade, um grande número de transferências de embriões pode ser executado por dia, sem comprometer a viabilidade da técnica de transferência.
\end{abstract}

Palavras-chave: novilha, perda gestacional, transferência de embriões

\begin{abstract}
We evaluated the results from 1100 embryo transfers performed from November 2008 to February 2009 by a commercial embryo transfer company. 1/2 Holstein/Gir $(n=139)$ or 3/4 Holstein/Gir $(n=961)$ embryos in a grade of 1 and the eighth day (D8) for fresh transfer were used. The heifer recipients were $1 / 2$ Nelore/Simmental, synchronized using the following protocol: Day zero (D0) - intravaginal device with $1 \mathrm{~g}$ of progesterone $+2 \mathrm{mg}$ of estradiol benzoate (EB); Day five (D5) - application of $150 \mu \mathrm{g}$ of $D$ Cloprostenol $\left(P_{G} F_{2 \alpha}\right)+400 U I$ of equine chorionic gonadotropin (eCG); Day eight (D8) - progesterone device removal and Day nine (D9) - application of $1 \mathrm{mg}$ of EB. The effects of genetic group, embryo's stage of development and cultivation time, side of the corpus luteum $(C L)$, bull, number of previous transfers in each recipient and sequence of hours spent with transfer on the pregnancy rate and loss of gestation were analyzed. Only the embryo's cultivation time influenced the pregnancy rate. It is concluded that if using high quality embryos, a larger number of embryo transfers can be executed per day without compromising the viability of technology transfer.
\end{abstract}

Keywords: heifer, pregnancy loss, embryo transfer

Recebido em 8 de novembro de 2011

Aceito em 22 de novembro de 2012

*Autor para correspondência (corresponding author)

E-mail: carlacristian_vet@yahoo.com.br 


\section{INTRODUÇÃO}

O aprimoramento e a crescente aplicação das biotecnologias ligadas à reprodução animal, como a transferência de embriões (TE) e a fertilização in vitro (FIV), contribuem para o aumento da eficiência reprodutiva dos rebanhos bovinos. A produção de embriões in vitro (PIV) consiste na manipulação dos gametas, em que os processos fisiológicos que acontecem naturalmente na fêmea são reproduzidos em condições laboratoriais.

A principal vantagem da PIV é o aumento significativo no número de crias produzidas por fêmea. Segundo Palhano (2008), é possível produzir cerca de 50 gestações por ano para cada doadora, sendo que fisiologicamente, nesse mesmo período, só seria possível obter um produto. Entre outras, destacam-se o aproveitamento de fêmeas com patologias do trato reprodutivo que as impeçam de reproduzir naturalmente, de animais senis, pré-púberes e gestantes, o melhoramento genético acelerado pela utilização de gametas de animais superiores e a facilidade de importação e exportação do material genético. A PIV para fins de pesquisa é importante para elucidar os fenômenos fisiológicos nos estágios iniciais do desenvolvimento embrionário.

A utilização da PIV em larga escala nos rebanhos comerciais é restrita devido ao alto custo operacional, ao tempo requerido na rotina de produção e à variação dos resultados obtidos pelos laboratórios; além disso, o monitoramento das doadoras, das receptoras e dos embriões deve ser rigoroso para garantir a eficiência da técnica. Outros fatores, como as perdas embrionárias, precoces ou tardias, e o nascimento de conceptos relativamente grandes, devem ser considerados, pois representam riscos à rentabilidade da técnica.

A taxa de sobrevivência embrionária após a inovulação pode ser influenciada por fatores como anormalidades cromossômicas, efeito da doadora, idade e qualidade dos embriões inovulados, método e local da transferência, sincronia doadora-receptora, estado nutricional e concentração sérica de progesterona na receptora, bem como estresse calórico (Hansen e Ealy, 1991).
Este trabalho foi realizado com o objetivo de avaliar os efeitos do grupo genético, o estágio de desenvolvimento e o tempo de cultivo do embrião, o lado do corpo lúteo (CL), o touro, o número de inovulações prévias realizadas em cada receptora e a sequência de horas de serviço gastas para realizar as inovulações sobre as taxas de prenhez e de perda de gestação em receptoras de embriões bovinos.

\section{MATERIAL E MÉTODOS}

$\mathrm{O}$ experimento foi realizado em uma fazenda comercial, localizada na BR-452, entre os municípios de Uberlândia e Tupaciguara, MG, de novembro de 2008 a fevereiro de 2009. Foram utilizadas como receptoras 940 novilhas $1 / 2$ Nelore/Simental e como doadoras 67 fêmeas das raças Gir e 1/2 Holandês/Gir.

Os ovócitos das doadoras foram coletados utilizando-se a técnica de aspiração folicular guiada por ultrassonografia, com intervalo de 15 dias. O número de ovócitos a ser aspirado em cada etapa foi calculado de acordo com o número de receptoras disponíveis, considerando-se o percentual de $33 \%$ de embriões produzidos a partir do total de ovócitos coletados. Após a coleta, os ovócitos foram classificados quanto à qualidade em graus um e dois (Leibfried e First, 1979). Os processos laboratoriais de maturação, fertilização e cultivo até a fase de blastocisto, com duração aproximada de nove dias, foram realizados por uma empresa terceirizada. No processo de fecundação in vitro foram utilizadas doses de sêmen sexado para fêmea de sete touros provados, todos da raça Holandesa, porém provenientes de centrais diferentes.

Para seleção das receptoras, foi realizada uma avaliação visual do estado geral dos animais, considerando-se escore de condição corporal, presença de ectoparasitos, entre outros. As novilhas selecionadas foram submetidas a exames ginecológico e sanitários para brucelose - com antígeno acidificado tamponado (AAT) e para tuberculose - teste da prega caudal.

O protocolo de sincronização do estro nas receptoras (Fig.1) iniciou-se no dia zero (D0), com a inserção do dispositivo intravaginal com $1 \mathrm{~g}$ de progesterona $\left(\mathrm{P}_{4}\right.$, Primer, Tecnopec $\left.{ }^{\circledR}\right)$ e aplicação intramuscular de $2 \mathrm{mg} \quad(2 \mathrm{~mL})$ de benzoato de estradiol (BE, Estrogin, 
Farmavet $^{\circledR}$ ). No quinto dia (D5), foi feita uma aplicação intramuscular de $150 \mu \mathrm{g}(2 \mathrm{~mL})$ de $\mathrm{D}$ cloprostenol, um análogo sintético da prostaglandina $\mathrm{F}_{2 \alpha}\left(\mathrm{PGF}_{2 \alpha}\right.$, Preloban, Intervet $\left.{ }^{\circledR}\right)$, juntamente a 400UI (2mL) de gonadotrofina coriônica equina (eCG, Folligon, Intervet ${ }^{\circledR}$ ). No oitavo dia (D8), o dispositivo de progesterona foi retirado, e no nono dia (D9) foi feita outra aplicação intramuscular de $1 \mathrm{mg}$ (1mL) de benzoato de estradiol.

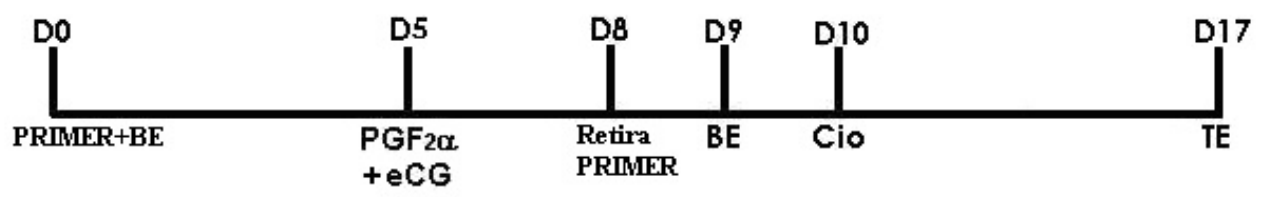

Figura 1. Representação esquemática do protocolo das receptoras de embrião.

No $17^{\circ}$ dia (D17), as receptoras tiveram seus ovários avaliados por ultrassonografia para determinar a presença do CL e o lado da ovulação. Aquelas que apresentaram um ou mais corpos lúteos estavam aptas para receberem os embriões, as que não possuíam CL, portanto não responderam ao protocolo, eram descartadas. A inovulação foi realizada no D17, totalizando, ao final do experimento, 1100 inovulações.

Cada receptora antes da inovulação foi anestesiada com $4 \mathrm{~mL}$ de cloridrato de lidocaína $2 \%$, via epidural baixa, e a vulva foi higienizada com água corrente e papel-toalha. A camisa sanitária plástica foi usada para prevenir a contaminação uterina e removida quando o inovulador alcançava o primeiro anel cervical. $\mathrm{O}$ inovulador, com a bainha e a palheta contendo o embrião, era levado à porção cranial do corno ipsilateral ao CL, onde o embrião foi depositado, tendo a palpação retal como ferramenta de orientação.

O diagnóstico de gestação foi feito 28 dias após a data da inovulação - 35 dias após a FIV -, e a sexagem fetal foi determinada pela localização do tubérculo genital aos 55 dias de gestação, ambos utilizando o aparelho de ultrassonografia Aloka $^{\circledR} \quad$ SSD-500. As vacas que foram confirmadas gestantes no diagnóstico de gestação, mas que estavam vazias no dia da sexagem, foram consideradas como tendo perda gestacional.

Os dados foram obtidos por meio de anotações em fichas padronizadas que continham informações como número da receptora, número total de transferências realizadas em cada receptora, nome e raça da doadora, nome do touro, data da inovulação, sequência da inovulação em cada dia de serviço, qualidade e estágio de desenvolvimento do embrião no dia da inovulação, lado do CL da receptora, data do diagnóstico de gestação, data da sexagem e sexo do embrião, perda de gestação, data de confirmação da gestação e data da entrega das receptoras.

As variáveis taxas de prenhez e de perda de gestação das receptoras foram analisadas por regressão logística, utilizando-se o programa SAS (Statistical..., 1988). Foram incluídas no modelo as variáveis: grupo genético, estágio de desenvolvimento e tempo de cultivo dos embriões, lado do corpo lúteo, touro, número de inovulações prévias realizadas em cada receptora e sequência de horas de serviço gastas para realizar as inovulações. Para todas as análises, a significância foi considerada quando $\mathrm{P} \leq 0,05$ e a tendência de efeito quando $0,05 \leq \mathrm{P} \leq 0,10$.

\section{RESULTADOS E DISCUSSÃO}

Das 1100 transferências de embriões realizadas, 636 receptoras foram diagnosticadas gestantes aos 35 dias $(57,8 \%)$, e destas, 574 receptoras foram confirmadas gestantes aos 55 dias $(52,1 \%)$, resultando em 62 perdas de gestação $(9,75 \%)$. Essa perda gestacional é semelhante aos valores encontrados por Galli et al. (2001), os quais afirmaram que, uma vez estabelecida a gestação, as perdas durante o primeiro trimestre podem chegar de 10 a $12 \%$.

Estudos que avaliaram mortalidade embrionária em bovinos entre os dias 25-28 e 42, com auxílio 
de ultrassonografia transretal, e mortalidade fetal precoce entre os dias 42 e 60-70, observaram resultados muito distintos, que, em geral, estavam associados à raça, idade, lactação, ou procedência dos embriões (Sartori e Dode, 2008).

A taxa de prenhez encontrada neste experimento foi mais alta que a descrita por Nonato Jr. et al. (2004), os quais obtiveram taxa de prenhez de $36,5 \%$ em um experimento com 849 receptoras. No entanto, alguns autores, como Niemann et al. (2002) e Rheingantz (2000), citaram índices de até $50 \%$ de prenhez, semelhante ao valor encontrado neste experimento.
Não foi detectado efeito do grupo genético do embrião nas taxas de prenhez e de perda de gestação (Tab. 1). As doadoras eram Gir puras ou 1/2 Holandês/Gir e os ovócitos foram fecundados com sêmen de touros da raça Holandesa. Com esse cruzamento, os embriões produzidos eram 1/2 Holandês/Gir ou 3/4 Holandês $1 / 4$ Gir. Essa variável não teve efeito sobre as taxas de prenhez e de perda de gestação. Segundo Gonçalves et al. (2008), essa variação é muito maior entre indivíduos - touro e doadora , assim como a interação entre eles, do que na variação racial.

Tabela 1. Taxas de prenhez e de perda de gestação com relação ao grupo genético do embrião utilizado em programa comercial de transferência de embriões

\begin{tabular}{lcc}
\hline $\begin{array}{l}\text { Grupo genético } \\
\text { do embrião }\end{array}$ & $\begin{array}{c}\text { Taxa de prenhez } \\
\%(\mathrm{n})\end{array}$ & $\begin{array}{c}\text { Taxa de perda de gestação } \\
\%(\mathrm{n})\end{array}$ \\
\hline 1/2 Holandês/Gir & $62,6(87 / 139)$ & $13,8(12 / 87)$ \\
3/4 Holandês/Gir & $57,0(549 / 961)$ & $9,1(50 / 549)$ \\
Valor P & 0,418 & 0,120 \\
\hline
\end{tabular}

O lado do CL não interferiu nas taxas de prenhez e de perda de gestação (Tab. 2). Mello (2004) encontrou taxas de prenhez equivalentes para receptoras que apresentavam CL do lado direito ou esquerdo, confirmando os dados obtidos neste experimento.

Tabela 2. Taxas de prenhez e de perda de gestação com relação ao lado do corpo lúteo da receptora utilizadas em programa comercial de transferência de embriões

\begin{tabular}{ccc}
\hline Lado do corpo lúteo & $\begin{array}{c}\text { Taxa de prenhez } \\
\%(\mathrm{n})\end{array}$ & $\begin{array}{c}\text { Taxa de perda de gestação } \\
\%(\mathrm{n})\end{array}$ \\
\hline Direito & $58,9(415 / 704)$ & $10,8(45 / 415)$ \\
Esquerdo & $55,4(219 / 396)$ & $7,8(17 / 219)$ \\
Valor P & 0,178 & 0,252 \\
\hline
\end{tabular}

Para analisar o estágio de desenvolvimento embrionário, os embriões foram classificados em embriões jovens, que são as mórulas e os blastocistos iniciais, embriões intermediários, que são os blastocistos e os blastocistos expandidos, e embriões adiantados, já nas fases de blastocisto em eclosão ou eclodidos. Não foi detectado efeito do grau de desenvolvimento do embrião nas taxas de prenhez e de perda gestacional (Tab. 3).

Untem et al. (2009) encontraram taxas de prenhez mais baixas para blastocistos iniciais $(6,2 \%)$, porém a taxa de prenhez total foi mais baixa $(29,3 \%)$ e o número de transferências realizadas também foi menor.

Tabela 3. Taxas de prenhez e de perda de gestação com relação ao estágio de desenvolvimento dos embriões utilizados em programa comercial de transferência de embriões

\begin{tabular}{lcc}
\hline $\begin{array}{l}\text { Estágio de desenvolvimento } \\
\text { do embrião }\end{array}$ & $\begin{array}{c}\text { Taxa de prenhez } \\
\%(\mathrm{n})\end{array}$ & $\begin{array}{c}\text { Taxa de perda de gestação } \\
\%(\mathrm{n})\end{array}$ \\
\hline Mórula/blastocisto inicial & $50,6(89 / 176)$ & $11,2(10 / 89)$ \\
Blastocisto/blastocisto expandido & $59,3(537 / 906)$ & $9,5(51 / 537)$ \\
Blastocisto eclodido & $47,1(8 / 17)$ & $12,5(1 / 8)$ \\
Valor P & 0,109 & 0,455 \\
\hline
\end{tabular}


Com relação à variável tempo de cultivo do embrião, neste experimento foram utilizados embriões D7, que levaram sete dias no laboratório para completar o desenvolvimento, e embriões atrasados, os chamados D8, que são embriões que demoraram um dia a mais para sofrer maturação e atingir o estágio de blastocisto apenas no oitavo dia de cultivo. Foi detectado efeito dessa variável na taxa de prenhez $(\mathrm{P}<0,0001)$ e a tendência dos embriões tardios resultarem em maior percentual de perda $(\mathrm{P}=0,094)$ (Tab. 4).
Resultados parecidos foram descritos no trabalho conduzido por Andreoti et al. (2009), que encontraram $42,99 \%$ de prenhez para embriões com desenvolvimento normal e $32,63 \%$ para os embriões D8, em um total de 670 embriões transferidos, indicando que a taxa de prenhez esperada para embriões tardios é inferior àquela observada nos embriões que apresentaram desenvolvimento normal.

Tabela 4. Taxas de prenhez e de perda de gestação com relação ao tempo de cultivo dos embriões utilizados em programa comercial de transferência de embriões

\begin{tabular}{ccc}
\hline $\begin{array}{c}\text { Tempo de cultivo } \\
\text { do embrião }\end{array}$ & $\begin{array}{c}\text { Taxa de prenhez } \\
\%(\mathrm{n})\end{array}$ & $\begin{array}{c}\text { Taxa de perda de gestação } \\
\%(\mathrm{n})\end{array}$ \\
\hline Embriões de sete dias (D7) & $59,2(577 / 975)$ & $8,6(50 / 577)$ \\
Embriões de oito dias (D8) & $45,6(57 / 125)$ & $21,0(12 / 57)$ \\
Valor P & $<0,0001$ & 0,094 \\
\hline
\end{tabular}

Não foi detectado efeito dos diferentes touros usados no experimento nas taxas de prenhez e de perda de gestação (Tab. 5). Um estudo parecido foi realizado ao se comparar o percentual de prenhez em 96702 receptoras utilizando-se sêmen de 20 touros diferentes, porém, neste estudo, foram encontradas diferenças nas taxas de prenhez, que variaram de 18 a $42 \%$, com um mínimo de 609 receptoras para cada touro (Accorsi et al., 2005).

Tabela 5. Taxas de prenhez e de perda embrionária com relação ao reprodutor utilizado para FIV em programa comercial de transferência de embriões

\begin{tabular}{lcc}
\hline Touro & $\begin{array}{c}\text { Taxa de prenhez } \\
\%(\mathrm{n})\end{array}$ & $\begin{array}{c}\text { Taxa de perda de gestação } \\
\%(\mathrm{n})\end{array}$ \\
\hline Touro 1 & $54,7(116 / 212)$ & $6,9(8 / 116)$ \\
Touro 2 & $61,0(94 / 154)$ & $5,3(5 / 94)$ \\
Touro 3 & $58,7(148 / 252)$ & $12,8(19 / 148)$ \\
Touro 4 & $59,8(177 / 297)$ & $13,6(24 / 177)$ \\
Touro 5 & $52,5(21 / 40)$ & $0(0 / 21)$ \\
Touro 6 & $54,0(67 / 124)$ & $9,0(6 / 67)$ \\
Touro 7 & $52,4(11 / 21)$ & $0(0 / 11)$ \\
Valor P & 0,963 & 0,437 \\
\hline
\end{tabular}

As taxas de prenhez e de perda de gestação foram analisadas com relação ao número de inovulações realizadas em cada receptora. Aquelas que falhavam em emprenhar eram novamente sincronizadas para evitar o descarte excessivo de receptoras. Foram avaliadas receptoras que participaram do programa pela primeira, segunda, terceira e quarta ou mais vezes. Não houve efeito do número de inovulações prévias das receptoras nas taxas de prenhez e de perda gestacional (Tab. 6).
Resultados semelhantes foram encontrados por Amaral et al. (2004), que também não encontraram diferenças na taxa de prenhez para receptoras utilizadas uma, duas ou três vezes. Essa variável é de importância considerável, pois indica a viabilidade de manter uma novilha receptora no programa de transferência por, pelo menos, quatro inovulações. 
Taxa de prenhez, e de perda...

Tabela 6. Taxas de prenhez e de perda embrionária com relação ao número de inovulações prévias realizadas nas receptoras de programa comercial de transferência de embriões

\begin{tabular}{lcc}
$\begin{array}{l}\text { Número de } \\
\text { inovulações prévias }\end{array}$ & $\begin{array}{c}\text { Taxa de prenhez } \\
\%(\mathrm{n})\end{array}$ & $\begin{array}{c}\text { Taxa de perda de gestação } \\
\%(\mathrm{n})\end{array}$ \\
\hline 1 & $56,6(322 / 569)$ & $10,9(35 / 322)$ \\
2 & $61,9(180 / 292)$ & $10,0(18 / 180)$ \\
3 & $55,5(61 / 110)$ & $9,8(6 / 61)$ \\
$\geq 4$ & $55,0(71 / 129)$ & $4,2(3 / 71)$ \\
Valor P & 0,615 & 0,322 \\
\hline
\end{tabular}

A última variável avaliada foi horas de serviço. Para fazer esse cálculo, foi considerada a média de 20 inovulações por hora de serviço e os animais foram divididos em quatro grupos. No primeiro grupo estão as primeiras 20 receptoras que foram inovuladas no dia. No segundo grupo estão as receptoras da $21^{\mathrm{a}}$ até a $40^{\mathrm{a}}$ inovulação do dia. No terceiro grupo foram colocadas as novilhas que receberam da $41^{\mathrm{a}}$ à $60^{\mathrm{a}}$ inovulação do dia de serviço, e no quarto grupo foram colocadas todas as novilhas a partir da $61^{\mathrm{a}}$ transferência do dia até a última. O número de inovulações variou de 20 a 120 por dia.

O número de horas de serviço não influenciou as taxas de prenhez e de perda gestacional, o que indica que é possível realizar várias inovulações em um mesmo dia sem comprometer as taxas de prenhez e de perda de gestação, desde que as inovulações sejam realizadas por um profissional treinado (Tab. 7). Na literatura não foram encontrados dados semelhantes.

Tabela 7. Taxas de prenhez e de perda embrionária com relação à sequência de horas de serviço em programa comercial de transferência de embriões

\begin{tabular}{lcc}
$\begin{array}{l}\text { Sequência das horas } \\
\text { de serviço* }\end{array}$ & $\begin{array}{c}\text { Taxa de prenhez } \\
\%(\mathrm{n})\end{array}$ & $\begin{array}{c}\text { Taxa de perda de gestação } \\
\%(\mathrm{n})\end{array}$ \\
\hline Primeira & $61,6(130 / 212)$ & $10,8(14 / 130)$ \\
Segunda & $52,2(94 / 180)$ & $9,6(9 / 94)$ \\
Terceira & $61,0(86 / 141)$ & $8,1(7 / 86)$ \\
Q Quarta & $57,1(324 / 567)$ & $9,9(32 / 324)$ \\
Valor P & 0,120 & 0,252 \\
\hline
\end{tabular}

* Considerando 20 inovulações por hora.

\section{CONCLUSÕES}

As variáveis grupo genético do embrião, lado do corpo lúteo, estágio de desenvolvimento do embrião, touro, número de inovulações prévias da receptora e sequência das horas de serviço gastas para realizar as inovulações não interferiram nas taxas de prenhez e de perda de gestação; apenas o tempo de cultivo do embrião influenciou a taxa de prenhez.

\section{AGRADECIMENTOS}

À Fapemig e à CAPES, pela concessão da bolsa de estudos.

\section{REFERÊNCIAS}

ACCORSI, M. F.; GONÇALVES, D.D.; FERRAZ, M.L. et al. Variação de touros na produção in vitro e a interação com diferentes doadoras. In: REUNIÃO ANUAL DA SOCIEDADE BRASILEIRA DE TECNOLOGIA DE EMBRIÕES, 19., Angra dos Reis, 2005. Anais... Angra dos Reis: Acta Scientiae Veterinariae, 2005. v.33. p.364.

AMARAL, J.B.; OBA, E.; PIRES, R.M.L. Prenhez em bovinos após transferência de embriões bipartidos e de hemi-embriões cultivados in vitro. In: REUNIÃO ANUAL DA SOCIEDADE BRASILEIRA DE TECNOLOGIA DE EMBRIÕES, 18., 2004, Barra Bonita, Anais... Barra Bonita: Acta Scientiae Veterinariae, 2004. v.32, p.194. 
ANDREOTI, M.; SPEGIORIN, M.R.; CUNHA, C.E.A. et al. Taxa de prenhez de embriões bovinos tardios transferidos no dia 8 de cultivo. In: CONGRESSO BRASILEIRO DE REPRODUÇÃO ANIMAL, 18., Belo Horizonte, 2009. Anais... Belo Horizonte: CBRA, 2009. v.18, p.352-352.

GALLI, C.; CROTTI, G.; NOTARI, C., et al. Embryo production by ovum pick up from live donors. Theriogenology, v.55, p.1341-1357, 2001.

GONÇALVES, P.B.D.; FIGUEIREDO, J.R.; FREITAS, V.J.F. Biotécnicas aplicadas à reprodução animal. 2.ed. São Paulo: Editora ROCA, 2008. p.299.

HANSEN, P.J.; EALY, A.D. Effects of heat stress on the establishment and maintenance of pregnancy in cattle. In: CONGRESSO BRASILEIRO DE REPRODUÇÃO ANIMAL, 1., Belo Horizonte. Anais... Belo Horizonte: CBRA, 1991. p.108-119.

LEIBFRIED, L.; FIRST, N.L. Characterization of bovine follicular oocytes and their ability to mature in vitro. J. Anim. Sci., v.48, p.76-86, 1979.

MELLO, V.F. Influência da receptora e do embrião sobre a viabilidade embrionária e sexo determinados através de ultra-sonografia. 2004. 105f. Dissertação (Mestrado em Medicina Veterinária e Zootecnia) Universidade de São Paulo, São Paulo.

NIEMANN, H.; WRENZYCKI, C.; LUCAS-HAHN, A. et al. Gene expression patterns in bovine in vitro produced and nuclear transfer - derived embryos and their implications for early development. Cloning and stem cells, v.4, p.29-38, 2002.
NONATO Jr., I.; RUFINO, F.A.; SANCHES, B.V. et $a l$. Produção de embriões em vacas nelore com a utilização associada de FIV e TE. In: REUNIÃO ANUAL DA SOCIEDADE BRASILEIRA DE TECNOLOGIA DE EMBRIÕES, 18., Barra Bonita, 2004, Anais... Barra Bonita: Acta Scientiae Veterinariae, 2004. v.32. p.95.

PALHANO, H.B. Reprodução em bovinosfisiopatologia, terapêutica, manejo e biotecnologia. 2.ed. Rio de Janeiro: Editora LF Livros, 2008, p.181224.

RHEINGANTZ, M.G.T. Fecundação in vitro, criopreservação de ovócitos e embriões e sexagem de embriões bovinos. Rev. Bras. Reprod. Anim., v.24, p.21-29, 2000.

SARTORI, R.; DODE, M.A.N. Mortalidade embrionária na IA, TE, FIV e clonagem. In: SIMPÓSIO INTERNACIONAL DE REPRODUÇÃO ANIMAL APLICADA, 3., 2008, Londrina. Anais ... Londrina: SIRAA, 2008. p.175-194.

STATISTICAL analysis system - SAS. USER'S Guide: Statistics, Version 6.02. Cary, NC: SAS Institute, 1988.

UNTEM, R.R.; PANTOJA, T.A.R.; ALVES, D.F.; NOGUEIRA, E. Taxa de prenhez de embriões produzidos in vitro conforme categoria embrionária. In: FEIRA DE PRODUÇÃO CIENTÍFICA DE MATO GROSSO DO SUL, 3., 2009, Campo Grande. Anais... Campo Grande: COMVET, 2009. 